\title{
openheart Community-based aortic stenosis detection: clinical and echocardiographic screening during influenza vaccination
}

\author{
Richard Paul Steeds (D) , ${ }^{1}$ Andrew Potter, ${ }^{2}$ Navjeet Mangat, ${ }^{3}$ Maren Fröhlich, ${ }^{4}$ \\ Cornelia Deutsch, ${ }^{4}$ Peter Bramlage (D) , ${ }^{4}$ Martin Thoenes ${ }^{5,6}$
}

\begin{abstract}
- Additional supplemental material is published online only. To view, please visit the journal online (http://dx.doi.org/10. 1136/openhrt-2021-001640).
\end{abstract}

To cite: Steeds RP, Potter A, Mangat $\mathrm{N}$, et al. Communitybased aortic stenosis detection: clinical and echocardiographic screening during influenza vaccination. Open Heart 2021;8:e001640. doi:10.1136/ openhrt-2021-001640

MF is deceased.

Received 2 March 2021 Accepted 14 May 2021

Check for updates

(c) Author(s) (or their employer(s)) 2021. Re-use permitted under CC BY-NC. No commercial re-use. See rights and permissions. Published by BMJ.

${ }^{1}$ Queen Elizabeth Hospital \& Institute of Cardiovascular Sciences, University of Birmingham, Birmingham, UK ${ }^{2}$ Whaddon Medical Centre, Bletchley, UK

${ }^{3}$ Swanswell Medical Centre, Birmingham, UK ${ }^{4}$ Institute for Pharmacology and Preventive Medicine, Cloppenburg, Germany ${ }^{5}$ Leman Research Institute Schaffhausen, Switzerland ${ }^{6}$ Medical Department, Edwards Lifesciences, Nyon, Switzerland

Correspondence to Dr Peter Bramlage; peter. bramlage@ippmed.de

\section{ABSTRACT}

Background Degenerative aortic stenosis (AS), the most common valvular heart disease in the Western world, is often diagnosed late when the mortality risk becomes substantial. We determined the feasibility of AS screening during influenza vaccination at general practitioner (GP) surgeries in the UK

Methods Consecutive subjects aged $>65$ years presenting to a GP for influenza vaccination underwent heart auscultation and 2D echocardiography (V-scan). Based on these findings, a patient management strategy was determined (referral to cardiologist, review within own practice or no follow-up measures) and status at 3 months was determined.

Results 167 patients were enrolled with a mean age of 75 years. On auscultation, a heart murmur was detected in 30 of $167(18 \%)$ patients (6 subjects with an AS-specific and 24 with a non-specific murmur). $75.2 \%$ of those with no murmur had a negative V-scan finding. Conversely, 16 of $30(53 \%)$ patients with any murmur had an abnormal $\mathrm{V}$-scan finding that was largely related to the aortic valve. Using clinical auscultation and V-scan screening, a decision not to pursue follow-up measures was taken in $147(88 \%)$ cases, whereas $18(10.8 \%)$ subjects were referred onward; with 5 of $18(27.8 \%)$ and 3 of $18(16.7 \%)$ being diagnosed with mild and moderate AS.

Conclusions Our pilot study confirms feasibility of valvular heart disease screening in the elderly in a primary care setting. Using simple and inexpensive diagnostic measures and 7.3 million UK inhabitants undergoing influenza vaccination, nationwide screening could potentially identify 130000 patients with moderate AS and a significant number of patients with severe AS.

\section{INTRODUCTION}

Degenerative aortic stenosis (AS) is a chronic, progressive and life-threatening disease and can present as aortic sclerosis, without obstruction to ventricular outflow, at one end of the spectrum to severe AS at the other. ${ }^{1}$ Patients with AS have a long time period during which severity (degree of narrowing of the aortic orifice with an associated increase in transvalvular pressure gradients) increases

\section{Key questions}

What is already known about this subject?

- Degenerative aortic stenosis (AS) is a chronic, progressive and life-threatening disease, which can be treated with aortic valve replacement. If AS is left untreated, patients experience progressive disability and are at increased risk of mortality. The diagnosis of AS remains challenging, despite this condition being the most common valvular heart disease (VHD) in the Western world.

What does this study add?

- We conducted a pilot study to determine both the feasibility and effectiveness of screening for AS during routine influenza vaccination at general practitioner surgeries in the UK. Our study confirmed that VHD screening of elderly patients in a primary care setting was feasible and resulted in the detection of mild and moderate AS. Furthermore, it used simple and inexpensive diagnostic measures and reached a significant proportion of elderly UK inhabitants undergoing influenza vaccination.

How might this impact on clinical practice?

- Implementation of a nationwide screening strategy, such as that outlined in this study, could potentially identify 130000 patients with moderate AS and a significant number of patients with severe AS

without symptoms. However, during this time, patient risk gradually increases and an estimated $50 \%$ of patients with mild or moderate AS have progressive valve calcification leading to haemodynamically severe AS. ${ }^{12}$ Once the gradient across the valve has increased beyond $20 \mathrm{~mm} \mathrm{Hg}$, which is the cut-off between mild and moderate AS in all major current guidelines, ${ }^{34}$ patients may become symptomatic, experience progressive disability and the mortality risk increases such that half of all patients will die within $2-5$ years without treatment. ${ }^{256}$ Aortic valve replacement (AVR) is the definitive treatment for 
patients with AS. ${ }^{3}$ However, the diagnosis of AS remains challenging, despite it being the most common valvular heart disease (VHD) in the Western world. ${ }^{7}$

Diagnosis of AS needs to be established early when the asymptomatic patient is well, decompensation has not taken place and intervention can be planned. Recent data, however, confirm that diagnosis of AS-affected patients is often missed, ${ }^{8}$ and by the time of referral for intervention $\sim 80 \%$ have severe symptoms and frequently impaired left ventricular (LV) function. ${ }^{9}{ }^{10}$ Symptoms of AS are difficult to interpret as they are non-specific and often attributed to various other pathologies in a predominantly elderly population. ${ }^{11}$ Furthermore, cardiac auscultation is not routinely performed by general practitioners (GPs) and lacks sensitivity. ${ }^{11}$ Echocardiography is the definitive test of choice for diagnosis and severity assessment of AS, but is a scarce and underused resource in the UK. ${ }^{12}$ Traditionally, transthoracic echocardiography has been performed in hospitals due to the use of large machines, limited portability and requirement for detailed skills. Technical advances have led to gradual miniaturisation and point-of-care echocardiography devices are now widely available and could be used for VHD screening. ${ }^{13}$ Recent preliminary data have shown the use of handheld devices to screen for AS in the community. ${ }^{14}$

The purpose of this study was to: (1) determine the feasibility of AS screening in a community population aged $>65$ years attending influenza vaccination using target auscultation and 2D echocardiography; (2) establish the detection rate of AS and clinical follow-up of subjects with a suspected AS diagnosis to evaluate diagnosis/treatment status after 3 months. This article is presented in accordance with the Strengthening the Reporting of Observational Studies in Epidemiology reporting checklist.

\section{METHODS}

\section{Study subjects and site characteristics}

This cross-sectional study took place between September and November 2017 at two GP practices (Buckinghamshire and Birmingham) in the UK. Consecutive subjects aged $>65$ years attending voluntary influenza vaccination were enrolled. Patients with known AS or previous AVR were excluded.

\section{Clinical investigation}

Clinical evaluation comprised three steps: (1) cardiac auscultation was performed in all subjects by the responsible physician. (2) This was followed by a target 2D echocardiography using a V-scan device (GE Healthcare, Wauwatosa, Wisconsin, USA). (3) A subset of patients was submitted for a repeated 2D echocardiography for validation, referred at the GP's discretion.

\section{Echocardiography}

The physicians received training on using the V-scan appropriately prior to the study. The aortic valve (AV) was assessed using 2D for semiquantitative assessment of: leaflet mobility (normal/reduced/increased), leaflet thickening (normal/reduced/increased) and severity of calcification (1, no calcification; 2 , mildly calcified (small isolated spots); 3, moderately calcified (multiple larger spots); and 4, heavily calcified (extensive thickening and calcification of all cusps)). ${ }^{15}$ Furthermore, the mitral valve was assessed for the presence of mitral regurgitation (MR, grading $0-4+$ ) and LV size (normal/dilated), function (normal/impaired) and the presence of LV hypertrophy (LVH).

\section{Documentation and clinical follow-up}

Patient characteristics, auscultation findings and 2D echocardiography results were documented using an electronic case report form. Subsequently, the primary care physician's decision regarding the clinical management strategy of patients with suspected AS was documented (no treatment/review within practice/referral). At 3 months, data on patient status (alive/dead/date of death), referral status (cardiology assessment/echocardiography/other) and VHD status in case of cardiology referral assessment were recorded.

\section{Statistics}

As this was an exploratory study, no formal sample size was determined, but was based on feasibility considerations. Population characteristics including demographic data and comorbidities were summarised as means and SDs for continuous variables and percentages for categorical data. Results for V-scan screening, 2D echocardiography, clinical management decision and 3-month follow-up are depicted as absolute patient numbers with percentages. No further statistical methods were applied.

\section{RESULTS}

\section{Patient characteristics}

In the influenza vaccination season 2017, 167 subjects were enrolled into the study; 88 were women (53\%) and the mean age was 75 years (table 1). Hypertension was highly prevalent and about one-fifth of patients had diabetes and/or coronary artery disease.

\section{Auscultation findings and referral}

During the patient visit, a heart auscultation was performed to detect any potential sign of (aortic) valve disease. This revealed a murmur in 30 patients, of which 6 were considered specific for AS and 24 murmurs were not considered AS specific. No heart murmur was noted during auscultation in most subjects $(n=137)$ (figure 1$)$.

\section{V-scan-based 2D echocardiography}

All patients underwent subsequent V-scan-based 2D echocardiography to consolidate the auscultation diagnosis. Overall, 8 patients had mildly restricted AV mobility (4.8\%), 26 had mild and 2 moderate AV thickening $(16.8 \%), 39$ had mild $(n=27)$ and moderate $(n=12)$ AV calcification (23.4\%). One patient had MR 2+ (table 2). Overall, $86.2 \%$ ( $\mathrm{n}=144)$ had normal LV function; 13.8\% $(\mathrm{n}=23)$ impaired LV function was not detected. LVH was 
Table 1 Patient characteristics at baseline (vaccination visit; $n=167$ )

n (\%) or mean \pm SD

\begin{tabular}{ll}
\hline Age (years) & $75 \pm 7$ \\
\hline Female gender & 53 \\
\hline Weight (kg) & $78 \pm 19$ \\
\hline Height & $167 \pm 10$ \\
\hline Diabetes mellitus & $31(19)$ \\
\hline Hypertension & $84(50)$ \\
\hline Smoking status & \\
\hline \multicolumn{1}{l}{ Current smoker } & $9(5)$ \\
\hline Never smoked & $79(47)$ \\
\hline Former smoker & $79(47)$ \\
\hline Hyperlipidaemia & $84(50)$ \\
\hline Coronary artery disease & $30(18)$ \\
\hline Murmurs on auscultation & \\
\hline \multicolumn{1}{l}{ AS-specific murmur } & $6(3.6)$ \\
\hline Unspecific murmur & $24(14.4)$ \\
\hline No murmur & $137(82.0)$ \\
\hline AS, aotic stenosi &
\end{tabular}

AS, aortic stenosis.

present in $1.8 \%(\mathrm{n}=3)$ of subjects and atrial fibrillation in $4.8 \%(\mathrm{n}=8)$.

Table 2 also shows how normal/abnormal V-scans correlate to AS-specific murmur/unspecific murmur or no murmur. Overall, the V-scan was normal in 117 (70.1\%) patients, defined as the absence of impaired AV mobility, thickening or calcification, and no MR (table 2). This applied to 14 patients who were previously diagnosed with a murmur and 103 patients in whom no murmur was detected with auscultation. A total of $75.2 \%$ of those with no murmur had a negative V-scan finding. Conversely, 16 of 30 patients with any murmur had an abnormal V-scan finding that was largely related to the AV. AS-specific murmur on auscultation had the highest rates of an abnormal V-scan (83.3\%; $\mathrm{n}=5)$.

Results of the V-scan were validated in a subsample of patients $(n=73)$ where physician findings and a reread by a National Health Service (NHS) cardiology reference centre was largely identical (online supplemental table 1). Concordance with results acquired by V-scan screening was confirmed in 65 subjects $(89 \%)$ for AV mobility, 57 subjects $(78.1 \%)$ for $\mathrm{AV}$ thickening and 60 subjects (82.2\%) for AV calcification. In 70 subjects (95.9\%), concordance in the MR assessment was confirmed. Concordance levels were equally high for the assessment of LV size $(73,100 \%)$, LV function $(73,98.6 \%)$ and $\mathrm{LVH}$ $(73,95.9 \%)$.

Determination of the sensitivity and specificity of heart auscultation was also assessed. Of the 137 patients with no murmur on auscultation, 103 had a normal V-scan (specificity $75.2 \%$ ). Patients with AS-specific murmur were correctly identified in five out of six patients with an abnormal V-scan later on (sensitivity $83.3 \%$ ). Patients with an unspecific murmur had a low sensitivity of only $45.8 \%$ (11 out of 24 patients).

\section{Clinical management decision of primary care physician}

Based on clinical auscultation and V-scan screening findings $(n=167)$, a decision not to pursue any follow-up measures was taken in $88 \%(\mathrm{n}=147)$ of cases, whereas 18 $(10.8 \%)$ subjects were referred onward (table 3$)$. For two patients $(1.2 \%)$, a decision to review within own practice was taken despite an abnormal V-scan. One patient was a 69-year-old woman who had never smoked, had no diabetes, no dyslipidaemia, no cardiovascular (CV)

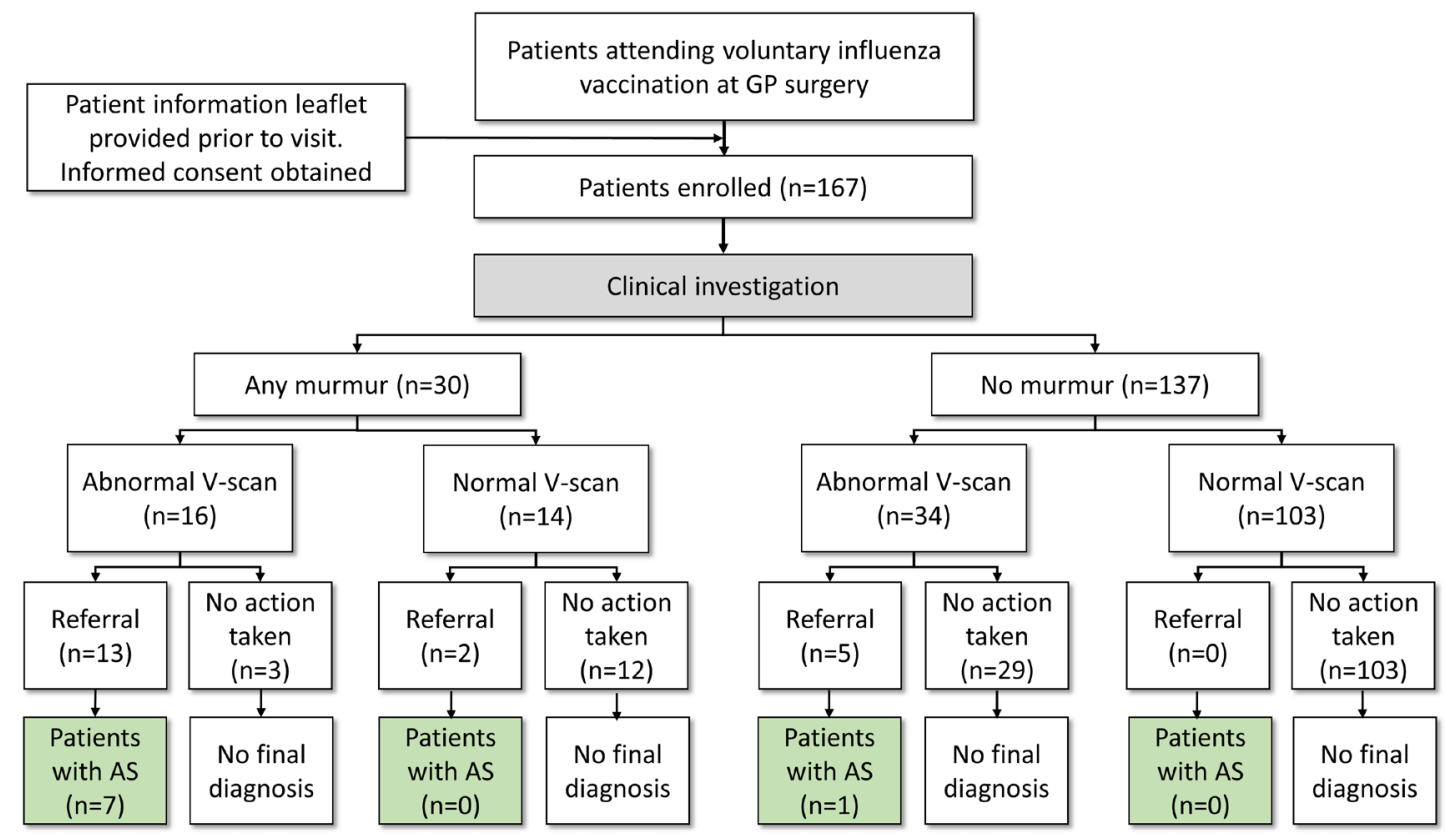

Figure 1 Patient classification based on auscultation and V-scan screening. AS, aortic stenosis; GP, general practitioner. 
Table 2 2D echocardiography $-V$-scan overall and with or without murmurs

\begin{tabular}{|c|c|c|c|c|}
\hline & $\begin{array}{l}\text { Total } \\
(n=167)\end{array}$ & $\begin{array}{l}\text { AS-specific murmur } \\
(\mathrm{n}=6)\end{array}$ & $\begin{array}{l}\text { Unspecific murmur } \\
(\mathrm{n}=24)\end{array}$ & $\begin{array}{l}\text { No murmur } \\
(\mathrm{n}=137)\end{array}$ \\
\hline $\begin{array}{l}\text { Normal V-scan (no impaired AV mobility, } \\
\text { thickening, calcification and no MR), } \mathrm{n}(\%)\end{array}$ & $117(70.1)$ & $1(16.7)$ & $13(54.2)$ & $103(75.2)$ \\
\hline $\begin{array}{l}\text { Abnormal V-scan (any of impaired AV mobility, } \\
\text { thickening, calcification and no MR), } n(\%)\end{array}$ & $50(29.9)$ & $5(83.3)$ & $11(45.8)$ & $34(24.8)$ \\
\hline $\begin{array}{l}\text { Impaired AV mobility, thickening or } \\
\text { calcification, } \mathrm{n}(\%)\end{array}$ & $50(29.9)$ & $5(83.3)$ & $11(45.8)$ & $34(24.8)$ \\
\hline Any MR, n (\%) & $1(2.0)$ & $0(0)$ & $1^{*}(4.2)$ & $0(0)$ \\
\hline \multicolumn{5}{|l|}{ AV mobility } \\
\hline Normal, n (\%) & $159(95.2)$ & $2(33.3)$ & $21(87.5)$ & $136(99.3)$ \\
\hline Mildly restricted, n (\%) & $8(4.8)$ & $4(66.7)$ & $3(12.5)$ & $1(0.7)$ \\
\hline Moderately restricted, n (\%) & $0(0)$ & $0(0)$ & $0(0)$ & $0(0)$ \\
\hline \multicolumn{5}{|l|}{ AV thickening } \\
\hline Normal, n (\%) & 139 (83.2) & $1(16.7)$ & $16(66.7)$ & $122(89.1)$ \\
\hline Mildly thickened, $\mathrm{n}(\%)$ & $26(15.6)$ & $4(66.7)$ & $7(29.2)$ & $15(10.9)$ \\
\hline Moderately thickened, n (\%) & $2(1.2)$ & $1(16.7)$ & $1(4.2)$ & $0(0)$ \\
\hline \multicolumn{5}{|l|}{ AV calcification } \\
\hline None, $\mathrm{n}(\%)$ & $128(76.6)$ & $3(50.0)$ & $14(58.3)$ & $111(81.0)$ \\
\hline Mildly calcified, $n$ (\%) & 27 (16.2) & $1(16.7)$ & $4(16.7)$ & $22(16.1)$ \\
\hline Moderately calcified, n (\%) & $12(7.2)$ & $2(33.3)$ & $6(25.0)$ & $4(2.9)$ \\
\hline Severely calcified, $n(\%)$ & $0(0)$ & $0(0)$ & $0(0)$ & $0(0)$ \\
\hline \multicolumn{5}{|l|}{ MR (severity) } \\
\hline None, $\mathrm{n}(\%)$ & 166 (99.4) & $6(100.0)$ & $23(95.8)$ & $137(100.0)$ \\
\hline $1+, \mathrm{n}(\%)$ & $0(0)$ & $0(0)$ & $0(0)$ & $0(0)$ \\
\hline $2+, n(\%)$ & $1(0.6)$ & $0(0)$ & $1(4.2)$ & $0(0)$ \\
\hline \multicolumn{5}{|l|}{ Left ventricular size } \\
\hline Normal, $n(\%)$ & $144(86.2)$ & $4(66.7)$ & $23(95.8)$ & $117(85.4)$ \\
\hline Dilated, $\mathrm{n}(\%)$ & $0(0)$ & $0(0)$ & $0(0)$ & $0(0)$ \\
\hline Not assessable, $n(\%)$ & $23(13.8)$ & $2(33.3)$ & $1(4.2)$ & $20(14.6)$ \\
\hline \multicolumn{5}{|l|}{ Left ventricular function } \\
\hline Normal, $n(\%)$ & $144(86.2)$ & $4(66.7)$ & $23(95.8)$ & $117(85.4)$ \\
\hline Impaired, $\mathrm{n}(\%)$ & $0(0)$ & $0(0)$ & $0(0)$ & $0(0)$ \\
\hline Not assessable, $\mathrm{n}(\%)$ & $23(13.8)$ & $2(33.3)$ & $1(4.2)$ & $20(14.6)$ \\
\hline \multicolumn{5}{|l|}{ Left ventricular hypertrophy } \\
\hline No, $n(\%)$ & 164 (98.2) & $6(100.0)$ & $24(100.0)$ & $134(97.8)$ \\
\hline Yes, n (\%) & $3(1.8)$ & $0(0)$ & $0(0)$ & $3(2.2)$ \\
\hline Not assessable, $\mathrm{n}(\%)$ & $0(0)$ & $0(0)$ & $0(0)$ & $0(0)$ \\
\hline AF during echocardiography, $n$ (\%) & $8(4.8)$ & $2(33.3)$ & $0(0)$ & $6(4.4)$ \\
\hline
\end{tabular}

*The patient MR also had impaired AV mobility as well.

$\mathrm{AF}$, atrial fibrillation; $\mathrm{AS}$, aortic stenosis; $\mathrm{AV}$, aortic valve; $\mathrm{MR}$, mitral regurgitation.

disease but had hypertension. The V-scan revealed mild $\mathrm{AV}$ thickening, moderate AV calcification but normal AV mobility and no MR. The other patient was an 85-year-old man, former smoker, without diabetes, hypertension, dyslipidaemia or CV disease. V-scan showed normal AV mobility and thickening, mild calcification and no MR.
From the cohort of subjects with a detected murmur $(\mathrm{n}=30), \quad 15(50 \%)$ were not referred, whereas 13 $(43.3 \%)$ subjects were referred and $2(6.7 \%)$ subjects were reviewed within own practices. Of the patients not referred, two had mildly calcified AV (online supplemental table 2). 


\begin{tabular}{|c|c|c|c|c|}
\hline & $\begin{array}{l}\text { Total } \\
(n=167)\end{array}$ & $\begin{array}{l}\text { AS-specific murmur } \\
(n=6)\end{array}$ & $\begin{array}{l}\text { Unspecific murmur } \\
(n=24)\end{array}$ & $\begin{array}{l}\text { No murmur } \\
(n=137)\end{array}$ \\
\hline Active decision not to treat, $\mathrm{n}(\%)$ & $147(88.0)$ & $2(33.3)$ & $13(54.2)$ & $132(96.4)$ \\
\hline Normal/abnormal V-scan (n/n) & $(115 / 32)$ & $(1 / 1)$ & $(11 / 2)$ & $(103 / 29)$ \\
\hline Referral, $\mathrm{n}(\%)$ & $18(10.8)$ & $4(66.7)$ & $9(37.5)$ & $5(3.6)$ \\
\hline Normal/abnormal V-scan (n/n) & $(2 / 16)$ & $(0 / 4)$ & $(2 / 7)$ & $(0 / 5)$ \\
\hline Review within practice, $\mathrm{n}(\%)$ & $2(1.2)$ & $0(0)$ & $2(8.3)$ & $0(0.0)$ \\
\hline Normal/abnormal V-scan (n/n) & $(0 / 2)$ & - & $(0 / 2)$ & - \\
\hline
\end{tabular}

AS, aortic stenosis.

In referred subjects $(\mathrm{n}=18)$, the majority had a murmur $(\mathrm{n}=13 ; 72.2 \%)$, whereas five $(27.8 \%)$ subjects were referred based only on the V-scan findings, with no cardiac murmur (table 3 ).

\section{Clinical follow-up at 3 months}

At 3-month follow-up, all 167 subjects were alive. In most subjects referred for standard 2D echocardiography, no evidence of severe AS could be established (10 of 18 patients, $55.6 \%)$, whereas 5 of $18(27.8 \%)$ and 3 of 18 $(16.7 \%)$ patients were diagnosed with mild and moderate AS, respectively (table 4 ).

\section{DISCUSSION}

\section{Summary}

Our pilot study in a cohort of 167 asymptomatic subjects confirms the feasibility of a novel and targeted approach to screen elderly patients during influenza vaccination in a GP office by using non-invasive and comparably cheap diagnostic tools, including heart auscultation and miniaturised echocardiography using target 2D imaging. Using this combined approach, our study identified mild AS in 5 of $167(3 \%)$ patients, moderate AS in 3 of 167

\begin{tabular}{lll}
\hline \multicolumn{1}{l}{ Table 4 Follow-up visit $(\mathrm{n}=167)$} & \\
\hline \multicolumn{1}{c}{$\mathbf{n}$} & $\%$ \\
\hline $\begin{array}{l}\text { Patient alive } \\
\begin{array}{l}\text { Acute or emergency admission since } \\
\text { vaccination clinic }\end{array}\end{array}$ & 167 & 100 \\
$\begin{array}{l}\text { Has the patient been referred since } \\
\text { vaccination clinic }\end{array}$ & 18 & 2.4 \\
$\begin{array}{l}\text { Repeated echocardiography } \\
\text { performed }\end{array}$ & 18 & 10.8 \\
$\quad$ AS confirmed & & \\
\hline No & $10 / 18$ & 55.6 \\
\hline Mild AS & $5 / 18$ & 27.8 \\
\hline Moderate AS & $3 / 18$ & 16.7 \\
\hline Severe AS & $0 / 18$ & 0 \\
\hline Other significant findings & $2 / 18$ & 11.1 \\
\hline Abnormal/impaired LV & $2 / 18$ & 11.1 \\
\hline
\end{tabular}

AS, aortic stenosis; LV, left ventricle.
(2\%) patients and MR 2+ in 1 patient. Most patients were identified with auscultation, although target V-scan 2D imaging not only increased the detection of those with abnormal valve function but also identified a cohort of those aged $>65$ years with AV calcification, which is a known predictor of AS progression of equivalent strength to maximal velocity. ${ }^{15}$

\section{Comparison with existing literature}

Degenerative AS represents an increasing threat, given the burgeoning elderly population, with risk increasing from the earliest stages of disease. By the time patients with severe AS present for surgery or percutaneous intervention, the majority have severe symptoms and/ or impaired LV function, which are associated with increased perioperative and post-intervention morbidity and mortality. ${ }^{5}$ Healthcare providers, therefore, need to focus on early diagnosis, reflected in the recent demands for community-based diagnosis at primary care level (NHS Long-Term Plan). ${ }^{16}$ Large-scale screening using formal echocardiography in the community by fully trained sonographers revealed that undiagnosed valve disease is common, with clinically significant abnormalities in $>6 \% .{ }^{17}$ Similar findings were achieved in a systematic large-scale screening in $\sim 30000$ patients with conventional 2D echocardiography on referral to hospital $(7.2 \%) \cdot{ }^{18}$ Although both studies showed a higher AS prevalence than our study, they used full-time sonographers using fully equipped echocardiography machines, while our study used full-time primary care physicians using target 2D scanning alone. Whole population screening using formal echocardiography in those aged $>65$ years is unlikely as, although the test is relatively cheap, there is a shortage of the required highly skilled accredited sonographers in the UK. A study in Norway by Lindekleiv et al used echocardiographic screening in the general population to improve long-term survival or reduce the risk of CV disease. Over a 15-year follow-up, this study showed that screening the general population did not impact on mortality of the risk of myocardial infarction or stroke. ${ }^{19}$ Assessing more targeted populations, however, might be more beneficial. The study by Fabich $e t a l$ showed that GP referrals of patients for quick scans were able to detect clinically unexpected pathology; a move consistent with the global move to use handheld ultrasound machines 
as an extension of clinical examinations. ${ }^{20}$ Our study supports these findings-GP-based heart auscultation and 2D echocardiography V-scans can be used to identify potential cardiac abnormalities, which will enable the appropriate monitoring and treatment of patients by specialist clinicians. Auscultation in combination with target V-scan offers an alternative, especially with potential improvements to the accuracy both of auscultation and detection of calcification on 2D imaging that are in progress using machine learning algorithms. ${ }^{821} 22$

\section{Referral rates}

A heart murmur was present in almost 1 out of 5 subjects screened (30 of 167 patients; 18\%) and the reason for referral of 13 of 18 patients, where 2D echocardiography was ultimately performed. AS could be detected in approximately half of those patients ( 8 of 18 patients; $44.4 \%$ ), confirming the low sensitivity and specificity of auscultation with regard to detecting VHD. ${ }^{23}$ Nevertheless, our data indicate a significant opportunity to identify patients with AS based on cardiac auscultation, as a positive auscultation finding would have a $20 \%$ likelihood of identifying a patient with mild or moderate AS (30 patients with a murmur, resulting in 13 referrals with a $44.5 \%$ likelihood of AS detection). In the majority of subjects where either a referral decision was taken or where subjects were supposed to be further reviewed within practice, a murmur was detected ( 15 of 20 patients), indicating that auscultation results were most likely the main driver for a referral decision. Conversely, the addition of the target V-scan clearly provided incremental benefit in two ways. First, 25\% (5 of 20) of patients without any murmur were referred based solely on positive V-scan screening, due to changes in AV morphology on two and predominantly $\mathrm{AV}$ thickening/calcification (15 of 20 patients and 16 of 20 patients, respectively). Second, a significant proportion of those with a murmur were not referred or were dealt with 'in-house'. The reasons behind non-referral or in-house care are uncertain but this decision was made by the GP who performed both auscultation and V-scan. Given the relative lack of changes in morphology, an added benefit of the combined approach using both auscultation and V-scan was that onward referral was avoided, although follow-up of outcomes for all patients screened was limited to only 3 months. While we do not have formal echocardiography on all those not referred, our data confirm a high level of concordance between the results of echocardiographic V-scan screening and conventional 2D echocardiography. ${ }^{24}$

\section{Strengths and limitations}

Our approach used the opportunity of individuals attending influenza vaccination to use auscultation and target V-scan resulting in the detection of AS with similar frequency to other studies. However, combining these two interventions within a single attendance was more challenging than expected. Many GP practices run their influenza clinics as mass vaccination sessions (eg, one practice aimed to vaccinate $600-700$ patients in a single morning session). The original aim of screening all attendees proved to be impossible for two reasons. First, ethical approval was granted for this study subject to participants receiving an information leaflet and being allowed time to read and consider participation before signed consent. This meant that information leaflets were sent out before their appointment, so that those consenting were 'preselected'. Second, although the study protocol was designed to minimise the time taken to auscultate and perform target V-scan (eg, by avoiding the requirement to undress the upper half of the body), the volume of patients attending influenza vaccination meant that participants had to be dealt with in a separate room to those just being vaccinated. While the study shows that screening during influenza vaccination is feasible, it would not be possible in practice to deliver this as part of a standard 'high throughput' approach. Finally, our study was limited to a follow-up of 3 months, it would be interesting to determine the impact of AS screening over a longer follow-up period.

\section{CONCLUSIONS}

As no cases of severe AS were detected, VHD screening in the setting of influenza vaccination has the potential to identify an 'at-risk' population, where regular echocardiographic follow-up could be indicated in those subjects with mild and moderate AS in order to monitor progression and initiate valve replacement therapy in a timely manner. A recent GP survey indicated almost 7.3 million UK inhabitants aged $>65$ years received influenza vaccination during the 2018/2019 season. Based on a prevalence of $1.8 \%$ for moderate AS in our dataset, nationwide AS screening in the UK would potentially identify about 130000 patients with moderate AS and a significant number of patients with severe AS, illustrating an important public health perspective of inexpensive VHD screening measures in the UK. ${ }^{25}$

\section{Twitter Richard Paul Steeds @Richard.Steeds}

Acknowledgements Data were captured using the s4trials software provided by Software for Trials Europe, Berlin, Germany. We are indebted to Dr Maren Fröhlich for her work on this project and it is with great sadness that we share news of her passing. We know she would have been delighted to see the results of her work being published.

Contributors RPS, AP, NM, MF, CD, PB and MT were all involved in the conception and design of the study. RPS, PB and MT drafted the manuscript and all other authors revised the article for important intellectual content. All authors gave final approval of the version published.

Funding This work was supported by a research grant from Edwards Lifesciences (Nyon, Switzerland), awarded to the Sponsor, the Institute for Pharmacology and Preventive Medicine (IPPMed, Cloppenburg, Germany).

Competing interests PB is the representative of the IPPMed, Cloppenburg, Germany. RPS received honoraria for advisory board meetings and speakers' honoraria from Edwards Lifesciences. MT is an employee of Edwards Lifesciences. AP, NM and CD have no conflicts of interest to disclose.

Patient consent for publication Not required.

Ethics approval The study received approval from the West Midlands and Solihull Ethics Committee (NRES 16/WM/0453). All subjects were provided with a patient information leaflet prior to their visit and written informed consent was obtained. 
Provenance and peer review Not commissioned; externally peer reviewed.

Data availability statement Data are available upon reasonable request. The datasets used and/or analysed during the current study are available from the corresponding author on reasonable request.

Open access This is an open access article distributed in accordance with the Creative Commons Attribution Non Commercial (CC BY-NC 4.0) license, which permits others to distribute, remix, adapt, build upon this work non-commercially, and license their derivative works on different terms, provided the original work is properly cited, appropriate credit is given, any changes made indicated, and the use is non-commercial. See: http://creativecommons.org/licenses/by-nc/4.0/.

\section{ORCID iDs}

Richard Paul Steeds http://orcid.org/0000-0001-5687-2535

Peter Bramlage http://orcid.org/0000-0003-4970-2110

\section{REFERENCES}

1 Otto CM. Aortic stenosis: even mild disease is significant. Eur Heart J 2004;25:185-7.

2 Strange G, Stewart S, Celermajer D, et al. Poor long-term survival in patients with moderate aortic stenosis. J Am Coll Cardiol 2019;74:1851-63.

3 Baumgartner H, Falk V, Bax JJ, et al. 2017 ESC/EACTS guidelines for the management of valvular heart disease. Eur Heart $J$ 2017;38:2739-91.

4 Nishimura RA, Otto CM, Bonow RO, et al. 2017 AHA/ACC focused update of the 2014 AHAVACC guideline for the management of patients with valvular heart disease: a report of the American College of Cardiology/American heart association Task force on clinical practice guidelines. Circulation 2017;135:e1159-95.

5 Otto CM, Prendergast B. Aortic-Valve stenosis - from patients at risk to severe valve obstruction. $N$ Engl J Med Overseas Ed 2014;371:744-56.

6 Ramaraj R, Sorrell VL. Degenerative aortic stenosis. BMJ 2008;336:550-5.

7 lung B, Delgado V, Rosenhek R, et al. Contemporary presentation and management of valvular heart disease: the EURObservational research programme valvular heart disease II survey. Circulation 2019;140:1156-1169.

8 Thoenes M, Bramlage P, Zamorano P, et al. Patient screening for early detection of aortic stenosis (AS)-review of current practice and future perspectives. J Thorac Dis 2018;10:5584-94.

9 Frey N, Steeds RP, Rudolph TK, et al. Symptoms, disease severity and treatment of adults with a new diagnosis of severe aortic stenosis. Heart 2019;105:1709-16.
10 Steeds RP, Lutz M, Thambyrajah J, et al. Facilitated data relay and effects on treatment of severe aortic stenosis in Europe. J Am Heart Assoc 2019;8:e013160.

11 Gardezi SKM, Myerson SG, Chambers J, et al. Cardiac auscultation poorly predicts the presence of valvular heart disease in asymptomatic primary care patients. Heart 2018;104:1832-5.

12 Chambers J, Kabir S, Cajeat E. Detection of heart disease by open access echocardiography: a retrospective analysis of general practice referrals. Br J Gen Pract 2014;64:e105-11.

13 Mirabel M, Celermajer D, Beraud A-S, et al. Pocket-sized focused cardiac ultrasound: strengths and limitations. Arch Cardiovasc Dis 2015;108:197-205.

14 Gulič TG, Makuc J, Prosen G, et al. Pocket-size imaging device as a screening tool for aortic stenosis. Wien Klin Wochenschr 2016;128:348-53.

15 Rosenhek R, Klaar U, Schemper M, et al. Mild and moderate aortic stenosis. natural history and risk stratification by echocardiography. Eur Heart J 2004;25:199-205.

16 NHS. NHS Long Term Plan 2019, 2020. Available: https://www. longtermplan.nhs.uk/

17 d'Arcy JL, Coffey S, Loudon MA, et al. Large-scale community echocardiographic screening reveals a major burden of undiagnosed valvular heart disease in older people: the OxVALVE population cohort study. Eur Heart J 2016;37:3515-22.

18 Ramos J, Monteagudo JM, González-Alujas T, et al. Large-Scale assessment of aortic stenosis: facing the next cardiac epidemic? Eur Heart J Cardiovasc Imaging 2018;19:1142-8.

19 Lindekleiv H, Løchen M-L, Mathiesen EB, et al. Echocardiographic screening of the general population and long-term survival: a randomized clinical study. JAMA Intern Med 2013;173:1592-8.

20 Fabich NC, Harrar H, Chambers JB. 'Quick-scan' cardiac ultrasound in a high-risk general practice population. Br J Cardiol 2016;23.

21 Thompson WR, Reinisch AJ, Unterberger MJ, et al. Artificial intelligence-assisted auscultation of heart murmurs: validation by virtual clinical trial. Pediatr Cardiol 2019;40:623-9.

22 Watrous RL, Thompson WR, Ackerman SJ. The impact of computerassisted auscultation on physician referrals of asymptomatic patients with heart murmurs. Clin Cardiol 2008;31:79-83.

23 Myerson S, Prendergast B, Gardezi S, et al. $136 \mathrm{Gp}$ auscultation for diagnosing valvular heart disease. Heart 2017;103:A101-2.

24 Kitada R, Fukuda S, Watanabe $\mathrm{H}$, et al. Diagnostic accuracy and cost-effectiveness of a pocket-sized transthoracic echocardiographic imaging device. Clin Cardiol 2013;36:603-10.

25 Public Health England. Seasonal influence vaccine uptake in GP patients: winter season 2018 to 2019, 2019. Available: https://assets. publishing.service.gov.uk/government/uploads/system/uploads/ attachment data/file/804889/Seasonal influenza vaccine uptake in_GP_patients_1819.pdf 